\title{
ANALYSIS OF INNOVATIVE INCREMENTAL COLD FORMING PROCESS FOR THE MANUFACTURING OF AEROSPACE ROTATING PARTS
}

\author{
Marcos Pérez \\ Advanced Forming Research Centre (AFRC), University of Strathclyde \\ Glasgow, UK
}

\section{ABSTRACT}

Cold rotary forging is an innovative incremental metal forming process whose main characteristic is that the workpiece is only partially in contact with a conical tool, reducing therefore the required forging loads. However, in spite of many benefits of such a process, wide industrial implementation of rotary forging is not possible without proper understanding of material behaviour. In the present work, the capability of rotary forging process was explored for the manufacturing of flared cylindrical parts by cold forming. Another main aim was to assess the cold formability of high-strength materials for aerospace applications (martensitic stainless steels) under incremental processes. In order to understand the impact of rotary forging on the final properties of formed components, microstructural and mechanical analysis were performed. Microstructural and hardness analysis were conducted on both axial and transverse sections along the cold formed flange in order to study the grain flow orientation and strain distribution. In a similar fashion, mechanical test specimens were machined from different positions and orientations along the rotary forged component. Further analysis was performed on the components in the astreated condition in order to understand the response of coldworked Jethete M152 components to subsequent heat treatments.

Microstructural and hardness analysis clearly reveals a strong grain reorientation and strain localization around "pickup" defects (material attached to the upper tool) observed on the flange top surface, close to the flange edge. These results suggest that an excessive deformation is localized during the early stages of the flange formation. Another characteristic feature found in the rotary forged parts is the presence of a buckling phenomenon which appears in later stages of the rotary forging process. Strain hardening along with the increasing flange length requires higher levels of forging loads to keep forming the flange. This results into a significant accumulation of compressive stresses in the transition region between the flange and the straight region. Gradually the resultant compressive force exceeds the critical buckling load, leading to the occurrence of the buckling phenomenon. This latter issue determines the limit of the cold flaring process. This can help to determine the maximum length of the flange part, achievable in this process, which is of great importance for the design of these manufacturing technologies. From the mechanical testing results, large differences were found as a function of both position and orientation (axial, transverse) throughout the rotary forged components (anisotropic properties). Concerning the impact of heat treatments on coldworked components, no differences were found in the as-treated condition, in terms of microstructural and mechanical properties between regions with a large difference in strain distribution. These results denote the normalizing effect of conventional hardening treatments on cold-worked Jethete M152 components, restoring the homogenous and isotropic properties across the whole component.

\section{INTRODUCTION}

Rotary forging is an incremental metal forming process where two dies have a common central axis and the upper tool, usually with a conical geometry, is inclined at a certain angle. This technology is representative of processes with local deformation (1). The inclined upper tool results in a partial contact area onto the upper surface of the workpiece, reducing contact stresses and the required forming force. The contact area moves circumferentially with the rotating die causing plastic deformation to spread incrementally throughout the workpiece. Rotary forging is attractive technology in the field of metal forming, because it has many advantages over any other processes, such as smaller deformation force, longer die life and less investment in equipment (2). The process of cold rotary forging provides additional advantages; it does not require heating, providing high accuracy and good quality of the formed surface (1).

The rotary forging process has been analyzed extensively from the mechanical point of view (3), (4), (5), (6) considering the complex interaction between tool design and workpiece, importance of nutation angle, etc. Other papers have analyzed the rotary forging process by means of simulation and numerical analysis (7), (8), (9). Despite the large amount of work done on 
rotary forging process, due to the periodical local loading and continuous shifting of the contact, the deformation mechanisms are reported to be very complex and have not been fully understood (1). It is clear that further work is required to fully understand and master a near-net-shape process as complex as rotary forging. The amount of papers which address the impact of rotary forging on microstructure and mechanical properties is very limited, especially for martensitic steels under incremental forming process such as rotary forging.

The objective of the present work is to explore the capability of rotary forging for the manufacturing of flared cylindrical parts, representative of real aerospace components, starting from hollow cylindrical preforms,. Another main aim is to analyze the cold formability of the Jethete M152 alloy (12\% Cr martensitic stainless steel).which is the material currently used through conventional manufacturing routes.

\section{METHODOLOGY}

Jethete M152 bars with $101.6 \mathrm{~mm}$ in diameter were supplied in the as-tempered condition. The chemical composition of this material is shown in Table 1. From these bars, cylindrical hollow preforms with dimensions of $\varnothing 100 \times 200$ (length) $\times 7.5 \mathrm{~mm}$ (thickness) were machined along the rolling direction. Figure 1 shows both the initial preform and the final rotary forged component analyzed in the present paper. This figure also indicates the rotary forging reference system, where ND (normal direction), TD (tangential direction) and ED (external direction) represent the axial/feed direction, the flange stretching along the circumferential direction, and the direction of lateral expansion of flange (increase of external diameter), respectively. Prior to rotary forging, the preforms were subjected to subcritical annealing treatments $\left(T<A_{\mathrm{c} 1}\right)$ in order to reduce both the loads required to cold forge Jethete M152 preforms and also to increase its ductility. The final hardness in as-annealed condition was about 280 HV2.

Table 1. Chemical composition of Jethete M152 alloy.

\begin{tabular}{|c|c|c|c|c|c|}
\hline $\mathrm{C}$ & $\mathrm{Mn}$ & $\mathrm{Ni}$ & $\mathrm{Cr}$ & $\mathrm{Mo}$ & $\mathrm{V}$ \\
\hline $0.11 \%$ & $0.68 \%$ & $2.67 \%$ & $11.41 \%$ & $1.56 \%$ & $0.28 \%$ \\
\hline
\end{tabular}

The rotary forging trials were conducted at the Advanced Forming Research Centre (AFRC, Glasgow) by using the MJC Rotary Forge equipment (RFN 200T - 4). The maximum tonnage of this equipment is $200 \mathrm{t}$, with a variable nutation angle ranging between $0^{\circ}-45^{\circ}$. A $45^{\circ}$ conical upper tool and a straight bottom tool were used. The bottom tool holds the preform with sufficient material upstanding from the tool to create the flange. The bottom tools also transmits the spindle speed to the preform with no need to fix it. Both the upper and bottom tools were machined from D2 tool steel. The trials were undertaken by nutating the upper tool to $17^{\circ}$ at the beginning of the rotary forging process. Molybdenum disulphide was selected as lubricant because of its low friction coefficient, greater load carrying capacity and stability up to temperatures of $400^{\circ} \mathrm{C}$. Figure 2 shows a schematic representation of the tools setup at the beginning and at end of the process. The sequence of the rotary forging process on the Jethete M152 cylindrical hollow parts are depicted in Figure 3. Jethete M152 rotary forged components were sectioned along the axial direction by water jet process for metallurgical work and hardness analysis. Sections of 5-10 mm thick were obtained (see Figure 4).

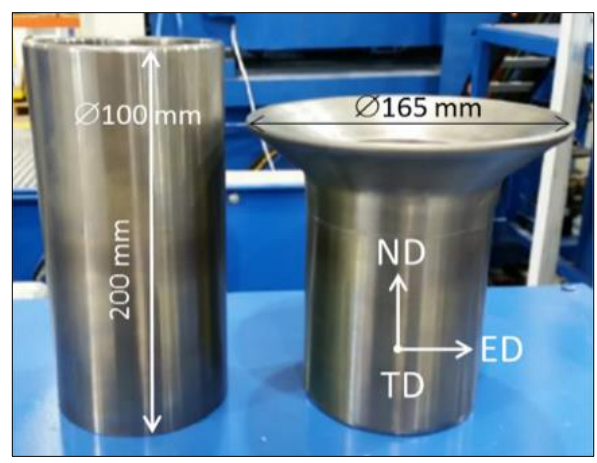

Figure 1. Cylindrical hollow part and rotary forged part.

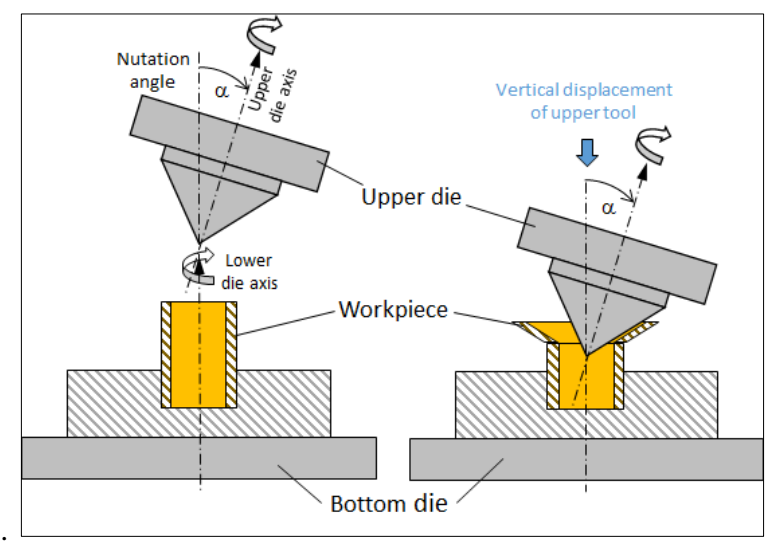

Figure 2. Schematic representation of rotary forging process

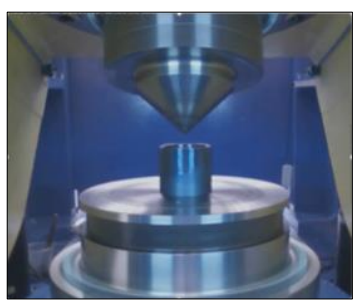

a) Nutation to $17^{\circ}$ (upper tool)

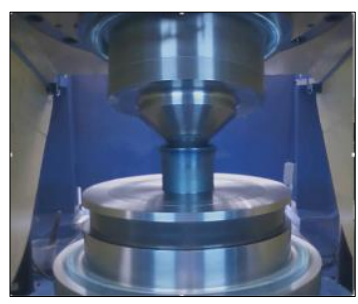

b) Axial compression stage, initial instants of flange formation

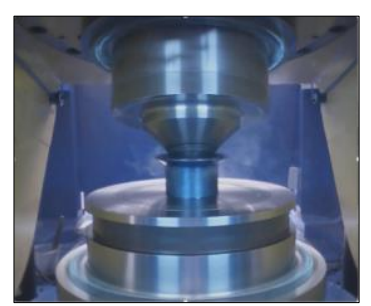

c) Steady-state stage of flange formation

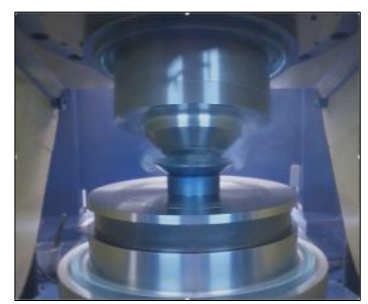

d) Final instants before the occurrence of axisymmetric buckling

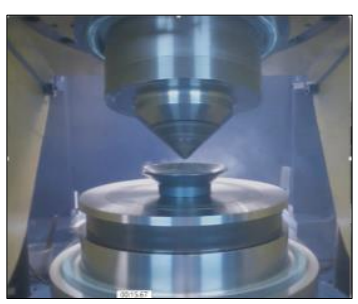

e) Final rotary forged part

Figure 3. Sequence of the rotary forging process of a Jethete M152 cylindrical hollow part. 


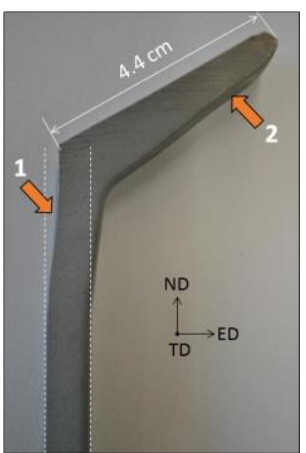

a)

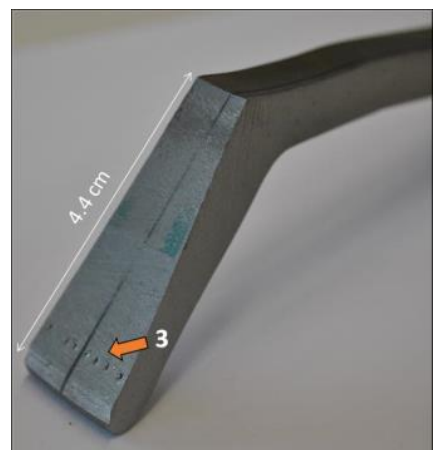

b)

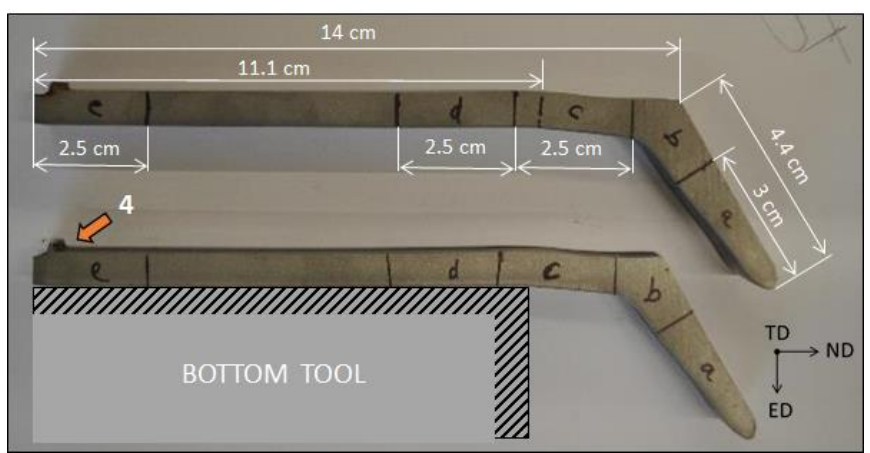

c)

Figure 4. Rotary forged axial sections for metallurgical and hardness analysis, where points $a, b, c$ and denote the buckling phenomenon, an abrupt reduction of flange thickness, pickup defects on the flange, and constrained deformation, respectively.

From Figure 4, four different features can be observed with the naked eye. Point 1 (Figure 4.a) indicates the presence of buckling in the transition region between the straight region and the flange, due to the high compressive stresses introduced during the later stages of the rotary forging process. Point 2 (Figure 4.a) marks an abrupt change in the flange thickness; Point 3 (Figure 4.b) indicates the presence of pickup defects located close to the flange edge, and Point 4 (Figure 4.c) shows material constrained at the bottom of the lower tool, due to the compressive stresses. Figure 4.c also shows several areas/sections/regions of rotary forged components (a,b,c,d \& e) considered for metallurgical and hardness analysis: Part $a$ : Area located in the flange with the highest levels of straining; Part b: Transition from the flange to the straight section; Part $c$ corresponds to the buckling region; Part $d$ : Section located in the straight section (base) with no apparent deformation; and Part e: Area similar to Part $\mathrm{d}$ with the peculiarity of the constrained material, as commented before (Point 4).

Hardness strategy: Hardness measurements were carried out on Zwick ZHV1 - micro Vickers hardness tester by applying a load of $2 \mathrm{~kg}$ (HV2). Hardness analysis was conducted in axial sections of rotary forged components in asforged and as-treated conditions, and at three different positions through the thickness: top/interior, middle, bottom/exterior. A distance of $1 \mathrm{~mm}$ among consecutive indentations was considered.

Microstructural analysis: The microstructure of Jethete M152 alloy was revealed by Villella's agent (etching). Optical microscopy was used in order to analyze both the grain flow (fiber orientation) and microstructure of rotary forged components. Scanning electron microscopy (SEM) was applied for the fracture surface analysis in tested mechanical specimens.

Heat treatment: In order to analyze the response of coldworked parts on subsequent heat treatments, rotary forged component were heat treated by solution treatment at $1050^{\circ} \mathrm{C}$ during $1 / 2$ hour, followed by tempering at $560^{\circ} \mathrm{C}$.

Mechanical testing: In order to assess the impact of both the rotary forging process and the subsequent heat treatment, tensile test specimens were obtained from rotary forged parts in the as-forged and as-treated conditions. Due to the complex geometry of the rotary forged parts and the reduced thickness of the flange, the smallest cylindrical specimen size (small-size specimen No.5) as defined by ASTM E8/E8M - 1 (10) was selected. Tensile tests were conducted in strain rate control at speeds of $0.002 \pm 0.001$ per minute. Figure 5 shows the different orientations (transverse \& axial) and locations (flange \& straight regions) of mechanical test specimens. At least, 2 test specimens per position and orientation were tested. Table 2 indicates the denomination of tensile specimens.

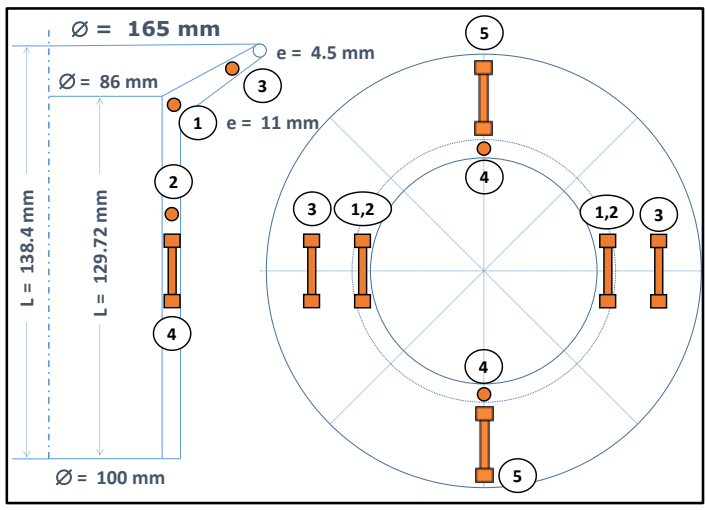

a) Distribution of axial and transverse test specimens on the rotary forged component

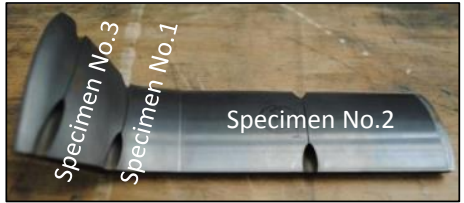

b) Transverse specimens

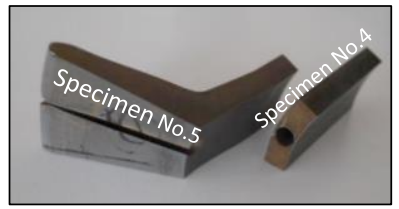

c) Axial specimens
Figure 5. Positions and locations in which the mechanical test specimens were obtained.

Table 2. Denomination of mechanical test specimens

\begin{tabular}{c|c|c|c|c|c}
\hline Orientation & \multicolumn{3}{|c|}{ Transverse } & \multicolumn{2}{c}{ Axial } \\
\hline Position & No.1 & No2 & No.3 & No.4 & No.5 \\
\hline Specimens & $1 \mathrm{~T} 1,1 \mathrm{~T} 2$ & $2 \mathrm{~T} 1,2 \mathrm{~T} 2$ & $3 \mathrm{~T} 1,3 \mathrm{~T} 2$ & 4A1,4A2 & 5A1,5A2 \\
\hline
\end{tabular}




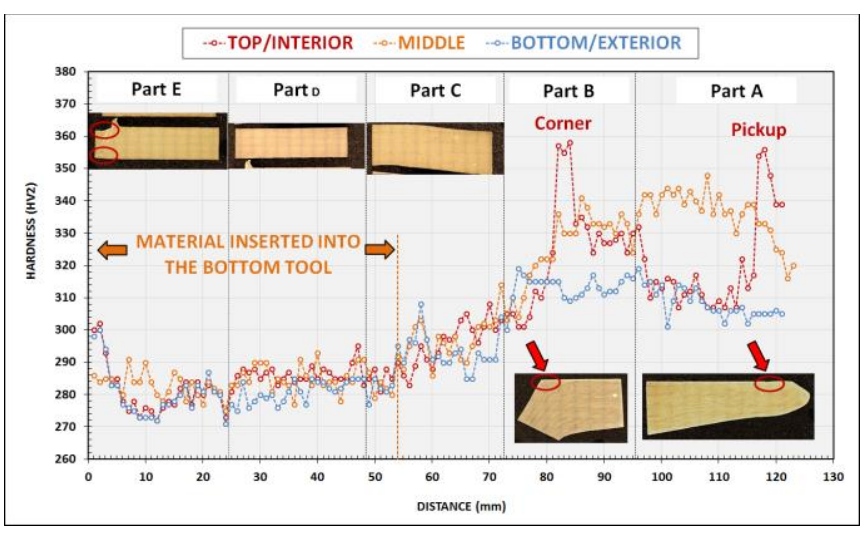

Figure 6. Hardness evolution in as-forged condition.

\section{RESULTS AND DISCUSSION}

\section{Hardness analysis}

The hardness evolution of a Jethete M152 rotary forged component is plotted in Figure 6 along the five selected sections (A,B,C,D,E, see Figure 4.c) and across the thickness. In parts $\mathrm{C}, \mathrm{D} \& \mathrm{E}$, all located in the straight region, an average hardness of about $280 \mathrm{HV} 2$ is observed with the exception of a slight peak of hardness at the very bottom of the forged components (Part E). This latter region is associated with material constrained against the bottom tool (see Figure 4.c, point d). Considering that $280 \mathrm{HV} 2$ is the hardness level found for Jethete M152 in as-annealed condition, it is assumed that these areas are free of significant deformation. In contrast, a slight but constant increase in hardness can be observed in Part C, from the point where the material projects from the bottom tool on (see orange dotted line in Figure 6). This region of increasing level of hardness corresponds to the buckling area.

In the case of those regions located in the flange (Parts A \& B), a sharp increase of hardness was found (Figure 6). However, a slight but constant reduction in hardness can be observed at middle and bottom positions along the flange, especially close to the flange edge/nose. Note that the flange formation requires a significant increase in the external diameter during the rotary forging process, from $100 \mathrm{~mm}$ in the preform to up to $165 \mathrm{~mm}$ at the end of the rotary forging process (Figure 1). This results into high levels of hoop (transverse) strain to be accommodated in the flange. Therefore, a continuous increase of hardness would be expected as a result of external diameter expansion. These results could be explained by the microstructural anisotropy effect and the orientation dependence of hardness (11), resulting from cold deformation/texture development.

Concerning the hardness distribution at the top surface (in contact with the upper tool), two sharp peaks of hardness are clearly identified $(\approx 350-360 \mathrm{HV} 2)$, see Figure 6: One close to the transition between the straight region and the flange (Part B), and another close to the pickup defect (Part A). As will be discussed later on, these peaks of hardness correspond to localized deformation which can be clearly detected by optical microscopy. With the exception of these two peaks of hardness,

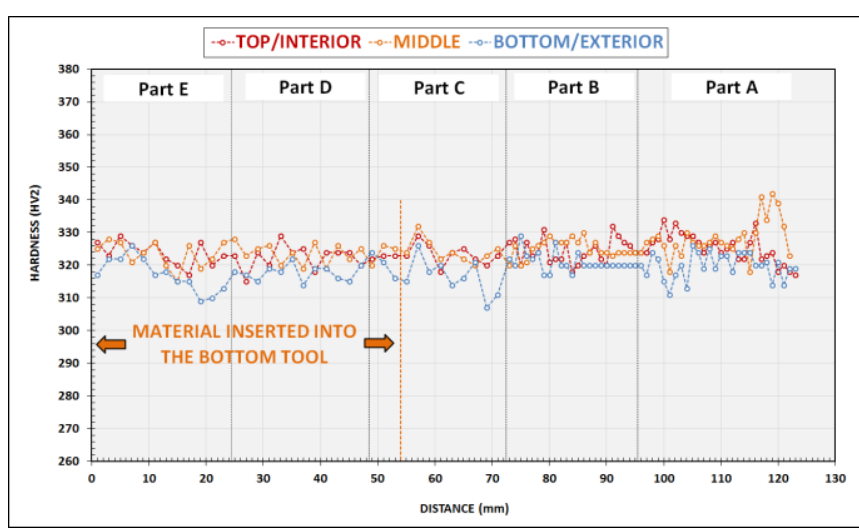

Figure 7. Hardness evolution in as-heat treated condition.

the middle position surprisingly presents the highest hardness level along the flange. Higher hardness levels were expected to be found close to the top surface due to the direct contact with the upper tool, but it seems it is not the case.

In as-treated condition (Figure 7), a constant and narrow hardness distribution (362 \pm 5 HV2) was found. Regardless of the amount of cold-work introduced in the course of the rotary forging process, no differences are observed between the flange and the straight region. These results suggest that homogeneous properties are achieved throughout the whole component after hardening and tempering treatments.

\section{Microstructural analysis}

A general overview of the band reorientation of microsegregation bands for Parts A and B in axial sections is depicted by Figure 8 . From this figure, several microstructural features are identified:

$\rightarrow$ The pickup defect close to the flange edge;

$\rightarrow$ The wavy banding close to the top surface associated with the incremental forming nature of rotary forging; and

$\rightarrow$ The different etching response in the transition region between the flange and the straight region, associated to localized deformation.

Figure 9 shows optical micrographs taken across the thickness (top, middle, bottom) at the flange center, in those positions identified in Figure 8 (color squares). In the as coldformed condition, the deformation structures are characterized by a strong reorientation and rotation of the initial grain boundaries (lath/martensitic packets). These grain boundaries adopt pancake-shape morphologies, elongated and aligned in specific directions. From Figure 9 it is possible to see how the alignment of the cold-worked microstructure seems to be rotating around the transverse direction with respect the top surface. Initially, the microstructural alignment presents an angle $(\alpha)$ close to $40^{\circ}$ at the top surface (Figure 9.a). However, this angle increases up to $70^{\circ}$ at bottom positions (Figure 9.c). Similar realignment was observed along the whole flange. This could be associated with bending effects that the workpiece experiences during the flange formation, in which the top/interior and bottom/exterior regions could be subjected to tension and compression forces, respectively. 


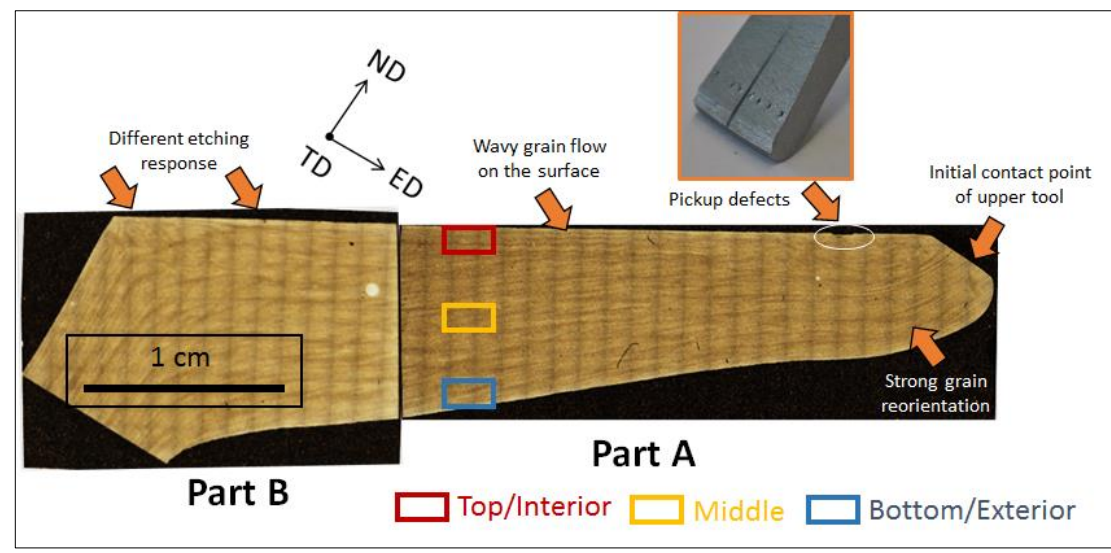

Figure 8. Fiber orientation and microstructural features on the flange of rotary forged component in as-forged condition.

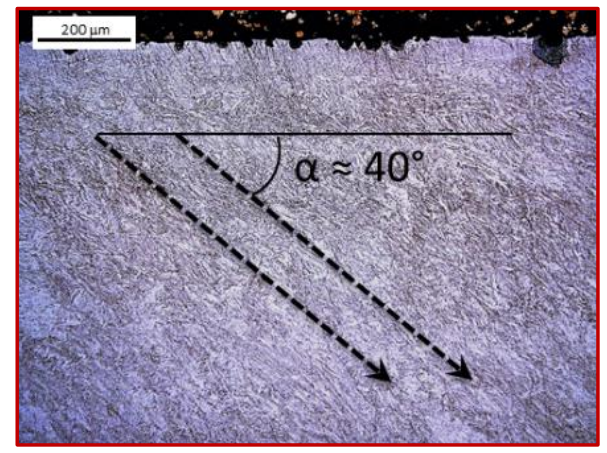

a) Top/interior region

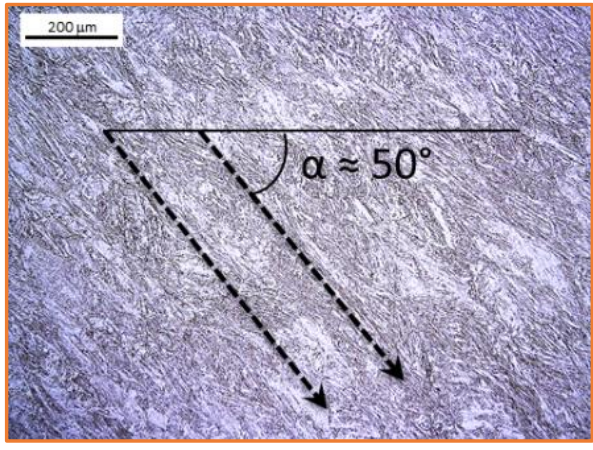

b) Middle section

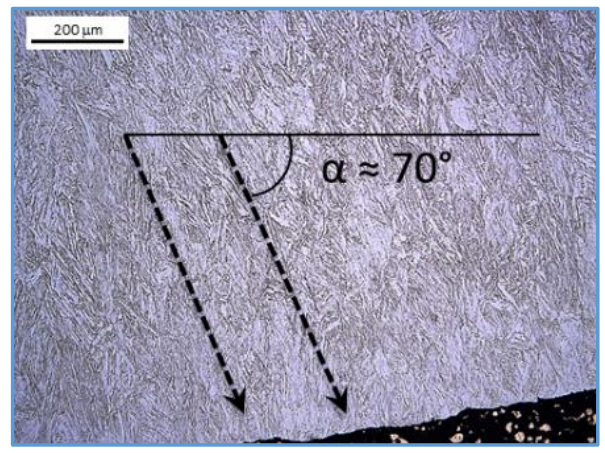

c) Bottom/exterior region

Figure 9. Microstructural alignment across the thickness in the central region of the flange (as-forged condition).

Figure 10 shows in detail the pickup defects (cracks) at two magnifications. A severe strain localization along with a strong grain reorientation around these defects can be observed. Initially, close to these pickup defects, the grain flow seems to be almost perpendicular to the top surface, but immediately the orientation of grain flow evolves forming an angle $(\alpha)$ of about $40^{\circ}$ to the top surface, as discussed previously in Figure 9.a. From this figure, it is also evident that the microcracks growth parallel/along to the microstructural alignment.

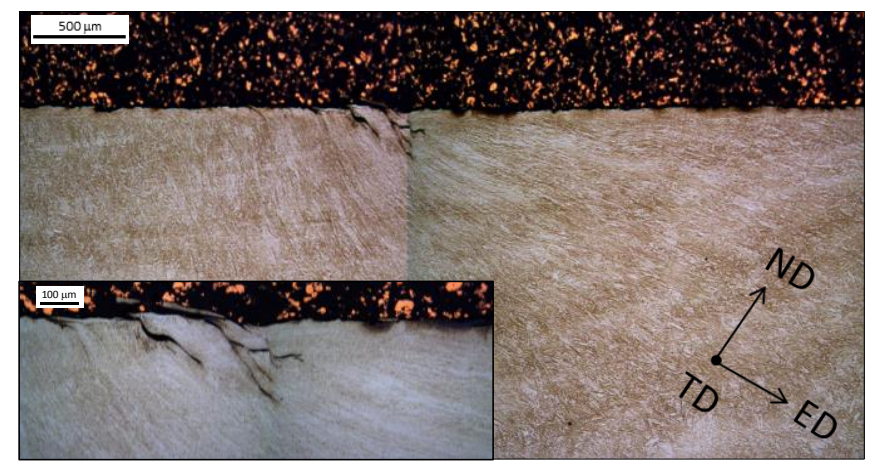

Figure 10.Pickup defect in rotary forged component.

These results clearly indicated the pickup defects are associated to high levels of localized deformation. It is highly probable that microstructural features, such as the abrupt reduction of the flange thickness (Point 2 in Figure 4.a) and the strong grain reorientation around the flange edge (see Figure 8) are associated with the high compression stresses introduced into the material in the early stages of the rotary forging process, before the stable formation of the flange (see Figure 3.c).

The impact of rotary forging on Jethete M152 microstructure was also analyzed in transverse orientations at four different positions (sections $\mathrm{AB}, \mathrm{BC}, \mathrm{CD} \& \mathrm{DE}$ ) as shown in Figure 11. A distance of $1 \mathrm{~cm}$ among consecutive sections was also considered. The first section (AB) is located close to the pickup defect.
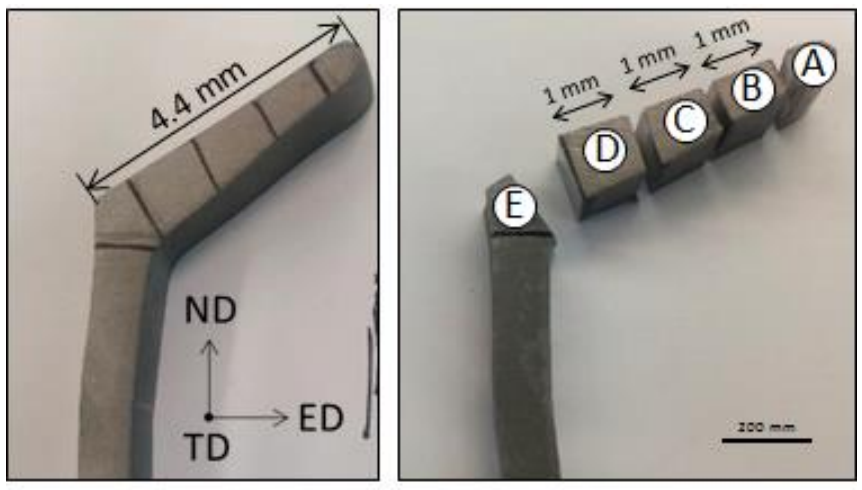

Figure 11. Transverse sections of Jethete M152 rotary forged components in as-forged condition. 


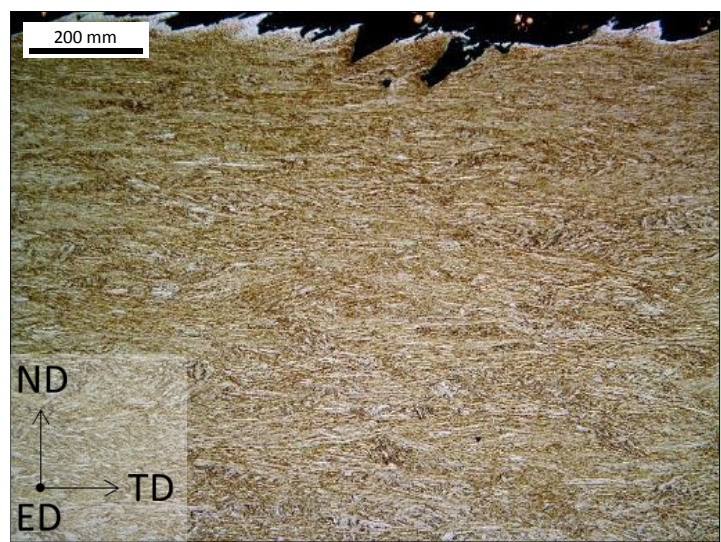

a) Section $A B$

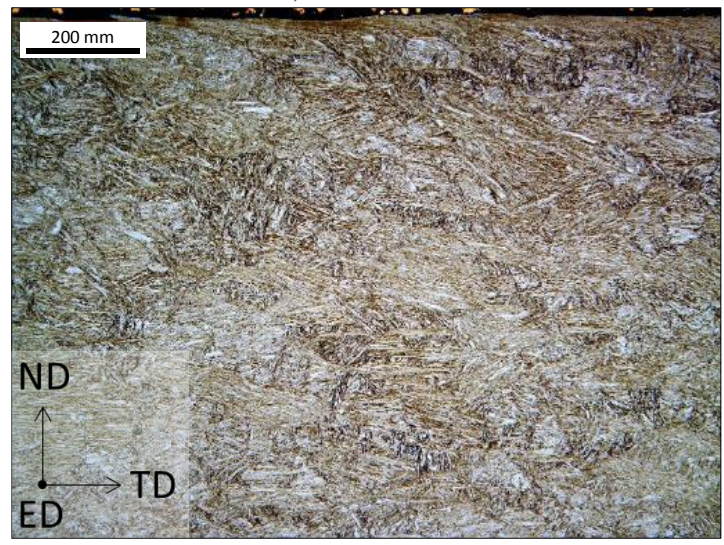

c) Section CD

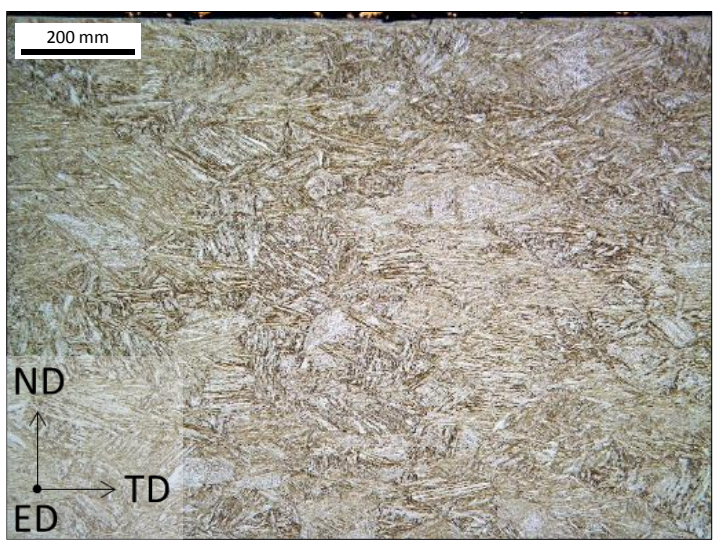

b) Section BC

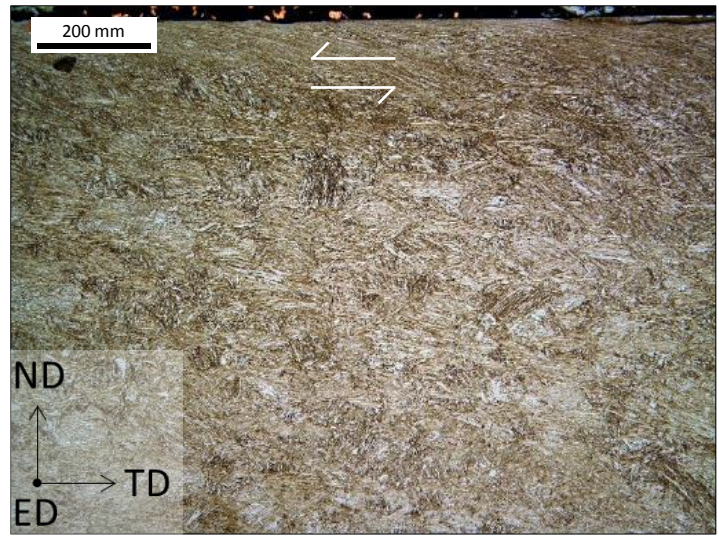

d) Section DE

Figure 12. Optical micrographs at top positions of transverse sections (as-forged condition).

Figure 12 shows optical micrographs taken close to the top surface for the four transverse sections. In sections $A B$ and $D E$, a significant amount of plastic deformation can be identified, in contrast with sections $\mathrm{BC}$ and $\mathrm{CD}$. These results are in agreement with the hardness results (Figure 6), where two peaks of hardness were found. The microstructure of section $\mathrm{AB}$ (Figure 12.a) is characterized by a strong reorientation of cold-worked martensite along the transverse direction. As commented before, a large amount of deformation is required to accommodate the increasing external diameter as the rotary forging process proceeds. In the case of the section DE (Figure 12.d), localized shear deformation on the surface can be observed aligned also along the transverse direction. This latter feature is associated with the relative movement of the upper tool against the preform, together with the large friction forces which act on the final stages of the rotary forging process. Note that in the course of the rotary forging process, strain hardening increases the strength levels of the material located at the flange along with the increasing flange length. Therefore, higher levels of forging loads are required to keep forming the flange. This results into the accumulation of compressive stresses in the transition region between the flange and the straight region. These results also explain both the peak in hardness (Figure 6) and the localized shear deformation (Figure 12.d) observed in this region. Subsequently, there is a point in which the resultant compressive force exceeds the critical buckling load, leading to the occurrence of the axisymmetric buckling phenomenon, and determining the cold formability limit of the flange.

Figure 13 shows macrographs of flange sections (Part A, B) in the as-heat treated condition. Similar features as those previously observed in as-forged condition (Figure 8) are detected. The reorientation of the micro-segregation bands, as a consequence of the rotary forging process, are retained after heat treatment. However, the cold-worked martensite has been fully replaced by tempered martensite, where no differences along the full component were found, in agreement with the hardness results (Figure 7). This latter observation is also confirmed by Figure 14, where micrographs were taken in those positions depicted in Figure 13. Homogeneous structures and grain size distributions can be found across the whole component, regardless of either the prior deformation or position across the thickness, and despite the large differences previously found in as-cold formed condition. The heat treated structures are characterized by a random orientation of the martensitic packets/laths. It is even possible to identify/infer the prior austenitic boundaries, showing equiaxed/hexagonal morphology. These results clearly indicated that the coldworked microstructure was removed after the hardening and tempering treatment, normalizing both the microstructure and also the mechanical properties as will be described later on. 


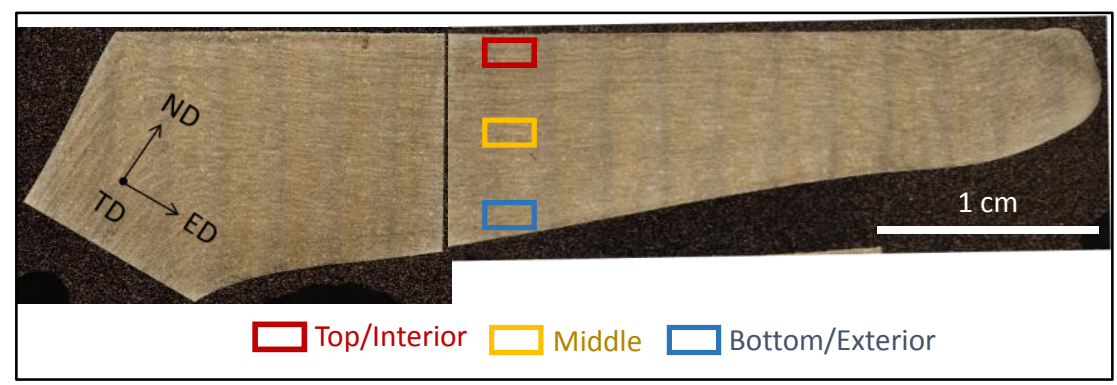

Figure 13. Part A and B (flange) of rotary forged component in as-treated condition

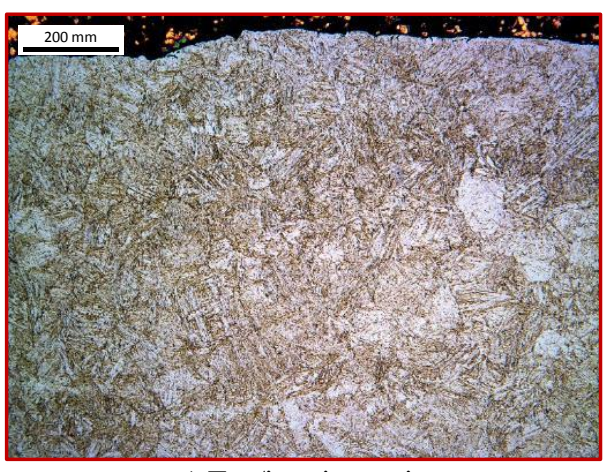

a) Top/interior region

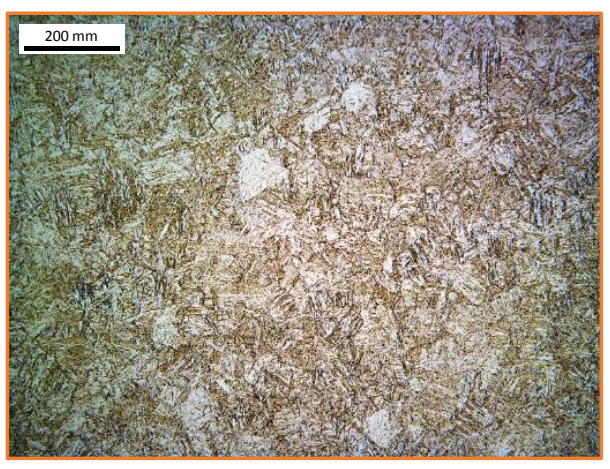

b) Middle section

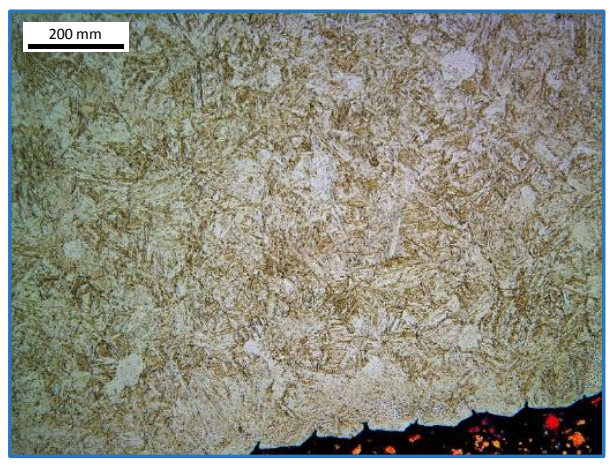

c) Bottom/exterior region

Figure 14. Microstructural alignment across the thickness in the central region of the flange (as-treated condition).

\section{Mechanical testing}

In the as-rotary forged condition, Figure 15 plots the engineering stress-strain curves from samples obtained in different positions and orientations, as shown in Figure 5. Comparing the stress-strain curves from specimens located at the straight region (see Figure 15.a): Position No.2 (transverse orientation) vs. No.4 (axial orientation), identical stress-strain curves were found. Considering that no apparent deformation was introduced in the course of rotary forging process in the straight regions, as demonstrated by the hardness results (Figure 6 ), these results denote the isotropic tensile properties of Jethete M152 in as-annealed condition. Values of yield stress $\left(\sigma_{\mathrm{ys}}\right)$ and ultimate tensile strength $\left(\sigma_{\mathrm{Ult}}\right)$ were in the range of $678-689$ $\mathrm{MPa}$ and 828-831 MPa, respectively, with total elongation values of about $15 \%$.

In the case of those specimens located in the flange (Positions No. 1, $3 \&$ 5), strong differences in the engineering stress-strain curves were observed as a function of both the orientation and position (Figure 15.b). Those samples located at position No.3 (flange edge, transverse direction) present the highest strength levels with the lowest elongation values. The yield stress and ultimate tensile strength increase up to 927 and $999 \mathrm{MPa}$, respectively, in comparison with positions No.2 and 4. In the case of elongation values, the total elongation drops to 7.7 and $8.8 \%$ with extremely low uniform elongation values of 1.1 and $1.3 \%$. In contrast, the specimens from position No.5 (axial direction) presents a remarkable uniform elongation (11.5 and $12.5 \%$ ), with values even higher than those samples located at position No.1 (10.2 and10.4\%) located in the transition between the flange and the straight region. Such differences can be explained by the large hoop strains introduced to accommodate the increasing external diameter of the flange, the transverse samples being aligned to this direction.

Figure 16 plots the evolution of yield stress $\left(\sigma_{\mathrm{ys}}\right)$ and ultimate tensile strength $\left(\sigma_{\mathrm{Ult}}\right)$ on the stress-strain curves of the transverse samples (Positions 1, $2 \& 3$ ). In this case, only 1 stress-strain curve per position is plotted for the sake of clarity. From these figures, there is a progressive increase in strength, from $678 \mathrm{MPa}\left(\sigma_{\mathrm{ys}}\right)$ and $828 \mathrm{MPa}\left(\sigma_{\mathrm{Ult}}\right)$ for position No.2, to $886 \& 925\left(\sigma_{\mathrm{ys}}\right)$ and $828 \& 999 \mathrm{MPa}\left(\sigma_{\mathrm{Ult}}\right)$ for positions No.1 $\& 3$, respectively. From this figure, it is also evident the significant reduction of uniform elongation $\left(\varepsilon_{\text {Uni }}\right)$. The uniform $\left(\varepsilon_{\text {Uni }}\right)$ and total elongation values $\left(\varepsilon_{\text {total }}\right)$ drop from $9.6\left(\varepsilon_{\text {Uni }}\right)$ and $15.8 \%\left(\varepsilon_{\text {total }}\right)$ for the position No.2, to $1.9 \& 1.3\left(\varepsilon_{\text {Uni }}\right)$ and 10.4 $\& 7.5 \%\left(\varepsilon_{\text {total }}\right)$ for positions $1 \& 3$, respectively. These results show how strongly the uniform elongation is affected by cold work in martensitic structures, in contrast with post-uniform elongation values, not being affected in a significant way. Postuniform values ranging $6.2-9.6 \%$ were found. The drastic reduction in uniform elongation for the position No.3 (flange edge), reaching the necking instability at very low levels of deformation, could indicate the limited remaining formability of the flange edge.

Figure 17 shows the fracture surface of the tensile samples from positions No.2 and 3, which represent those regions with minimum $(\varepsilon \approx 0$, annealed martensite $)$ and maximum deformation (cold-worked martensite). However, no differences in the (dimpled) fracture surface were found between both specimens, in agreement with the similar postuniform elongation values obtained across the whole component. 


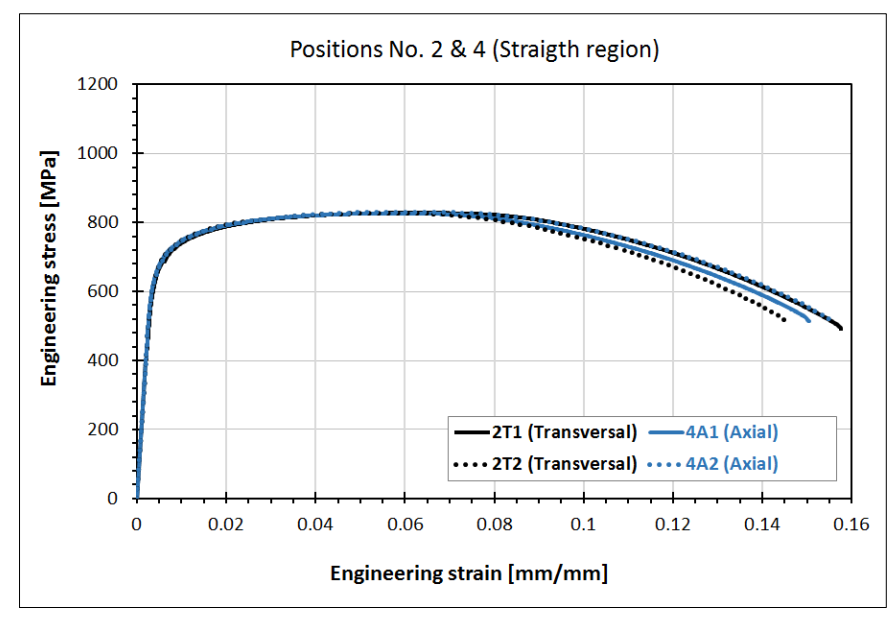

a)

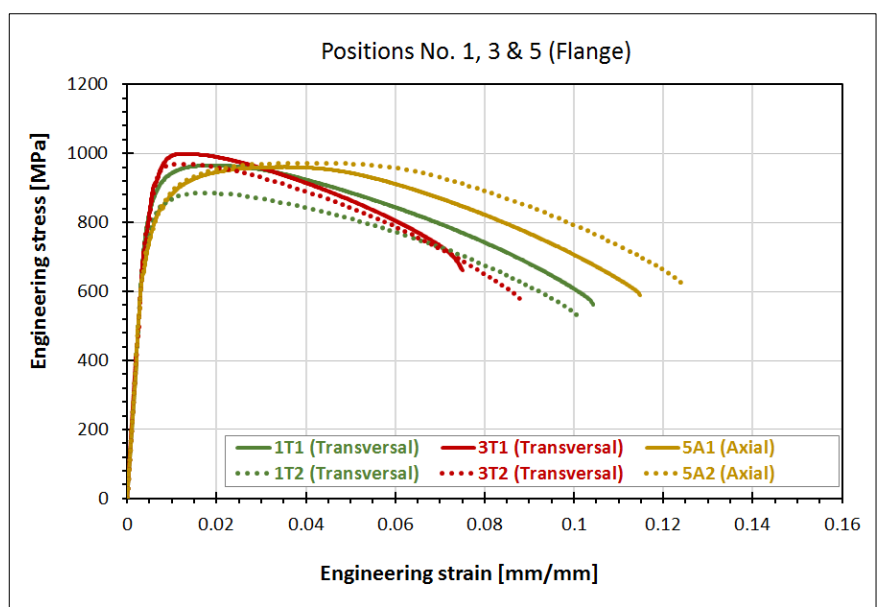

b)

Figure 15. Engineering stress - strain curves from different orientations (tangential, axial) and positions (flange, straight region) of rotary forged components in as-forged condition

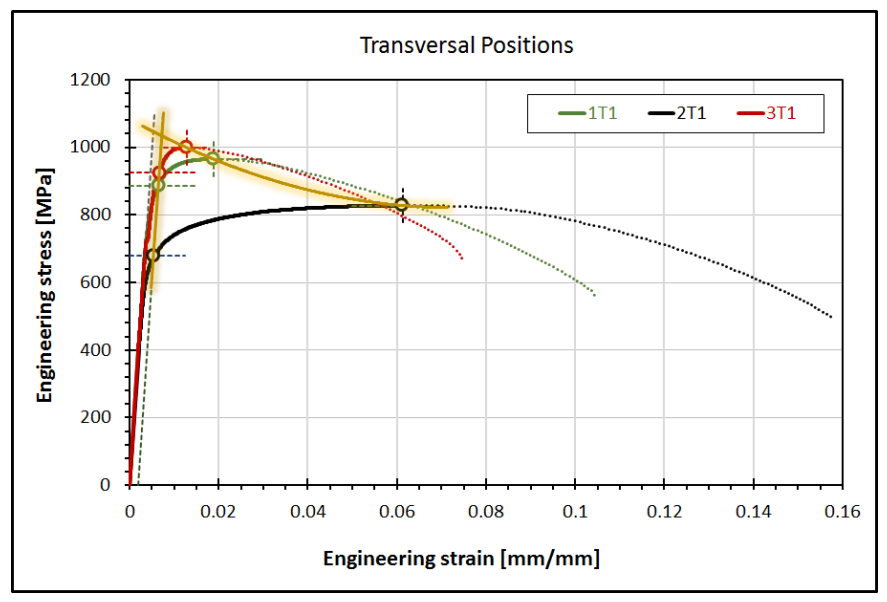

a)

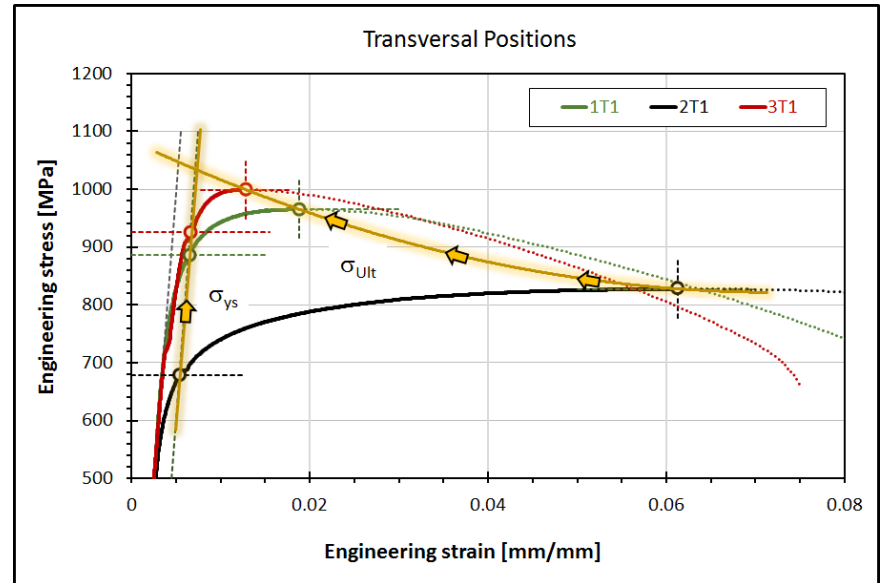

b)

Figure 16. Engineering stress - strain curves of transverse samples (Position 1,2 \& 3) in Jethete M152 rotary forged component in as-forged condition.

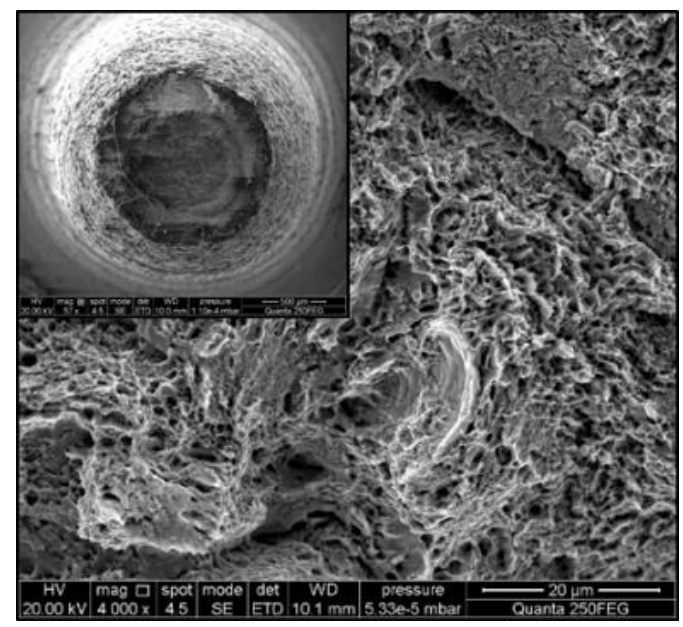

a) Position No.2 (no deformation)

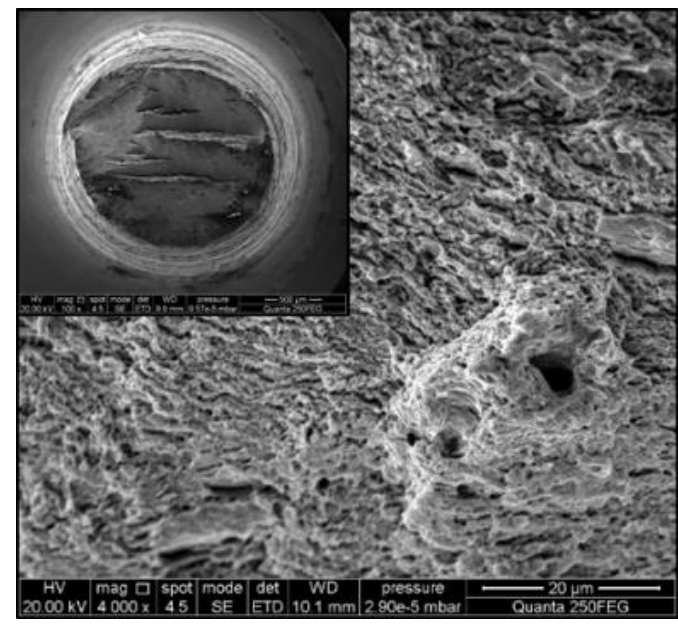

b) Position No.3 (maximum deformation)

Figure 17. Fracture surface of tested tensile tests from Jethete M152 rotary forged components in as-forged condition. 
Concerning the mechanism of fracture found from fracture surface analysis, it is assumed that the first stage of void initiation occurs at the second-phase particles, and at $\mathrm{Cr}_{23} \mathrm{C}_{6}$ carbides in particular. Note that the microstructure of low-C martensitic steels is reported to be a combination of lath martensite, carbides and retained austenite (11). The chromium carbides are formed during high tempering temperatures (400$550^{\circ} \mathrm{C}$ ) in what it is known as secondary hardening (12). Voids are initiated because carbides do not deform, and this forces the ductile matrix around the particle to deform more than normal. This, in turn, produces more strain hardening, thus creating higher stress in the matrix near the particles. When the stress becomes sufficiently large, the interface may separate, or the particle may crack. The second stage of ductile fracture is void growth, which is a strain-controlled process. Voids elongate as they grow, and the ligaments of the matrix material between the voids become thin, therefore, the final stage of ductile fracture is coalescence through the separation of the ligaments that link

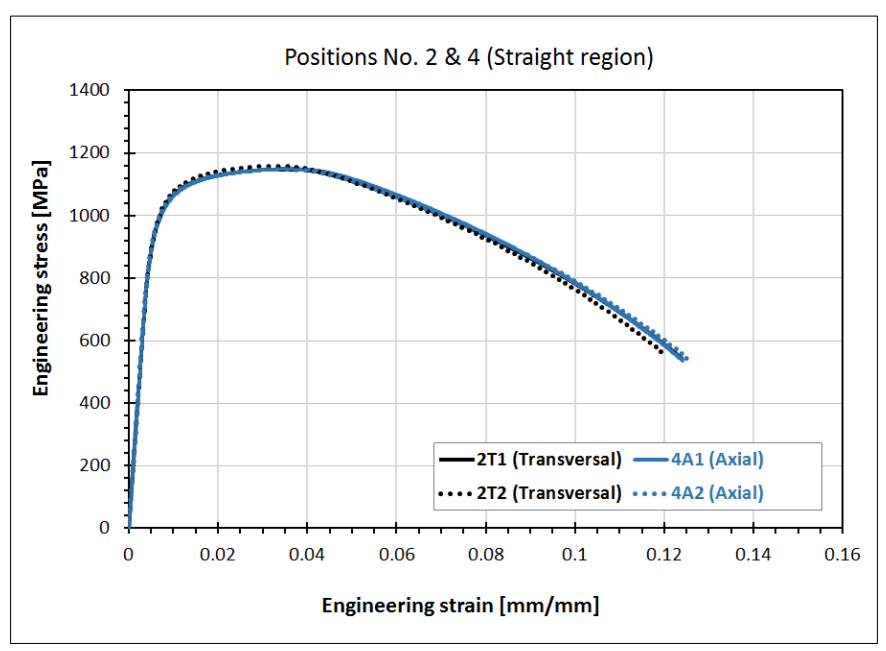

a) the growing voids. In the as-heat treated condition, engineering stress-strain curves from samples located at different positions and orientated in different directions (transverse vs. axial) are plotted in Figure 18. From these figures it is quite clear that all the tensile specimens depict the same engineering stress-strain curves, regardless the position and orientation, or in other words, regardless the prior history. The range of values of yield stress $\left(\sigma_{\mathrm{ys}}\right)$ and ultimate tensile strength $\left(\sigma_{\mathrm{Ult}}\right)$ are $990-1008$ $\mathrm{MPa}$ and 1143-1173 MPa, respectively. For elongation values, uniform $\left(\varepsilon_{\text {Uni }}\right)$ and post-uniform elongation $\left(\varepsilon_{\text {Post-uni }}\right)$ values are located between 3.2-3.8 and 8.7-9.3\%, respectively, with reductions in area of 51.2-53.8\%. This results are in agreement with hardness (Figure 7) and microstructural analysis results (Figure 13), in term of isotropic and homogeneous final properties. Finally, Figure 19 depicts the dimpled fracture surface of tensile samples from positions No.2 and 3, showing also a clear ductile fracture.

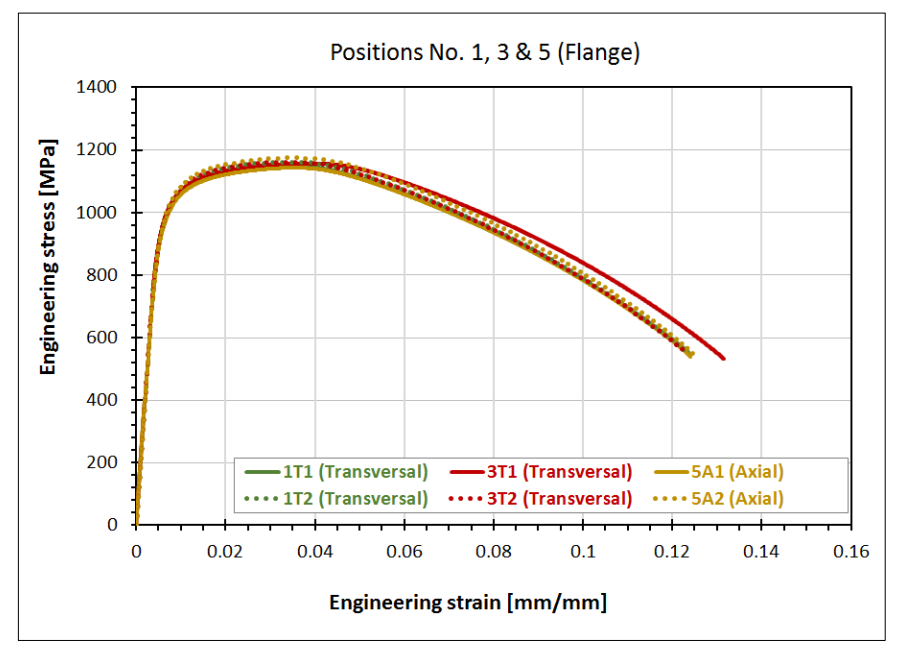

b)

Figure 18. Comparison among engineering stress - strain curves from different orientations (transverse, axial) and positions (straight region, flange) of Jethete M152 rotary forged components in as-heat treated condition.

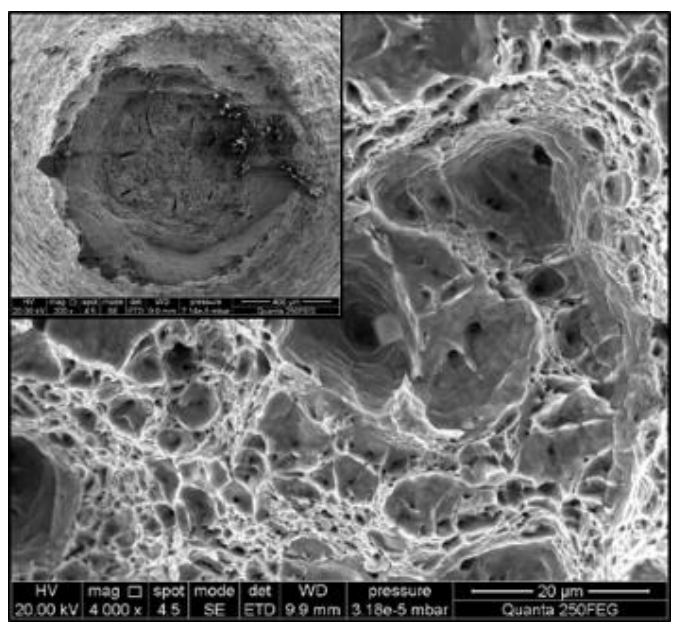

a) Position No.2 (no deformation)

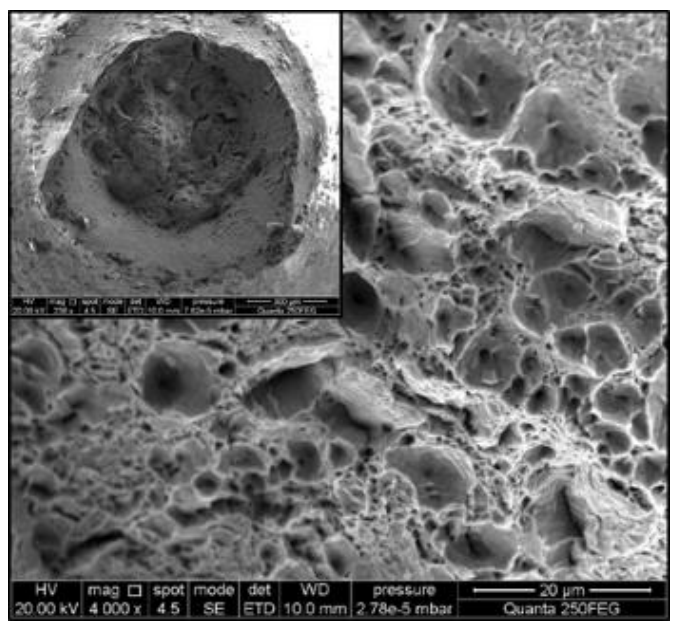

b) Position No.3 (maximum deformation)

Figure 19. Fracture surface of tested tensile tests from Jethete M152 rotary forged components in as-heat treated condition 


\section{CONCLUSIONS}

A pickup issue was detected on the surface of Jethete M152 rotary forged component, in contact with the upper tool and close to the flange edge. Material from the preform attached to the upper tool (D2 steel) was found, with the consequent indentation effect on the whole surface of the final component. A strong grain reorientation and strain localization along with the presence of cracks and a notable peak in hardness were observed around the pickup defects. These results suggest that the current forming method provokes an excessive and highly localized deformation during the early stages of the process before the stable formation of the flange.

Another feature to be remarked is the presence of a strong peak in hardness, also on the top surface, close to the transition area between the flange and the straight region. From microstructural analysis, localized shear deformation aligned with the transverse direction was observed. This deformation is associated with large friction forces and relative movement of the upper tool against the preform at the final stages of the forging process, prior to the occurrence of axisymmetric buckling phenomenon. Strain hardening along with the increasing flange length requires higher levels of forging loads to keep forming the flange. This results into the accumulation of compressive stresses which finally exceeds the critical buckling load, leading to the final appearance of the buckling phenomenon and determining the limit of cold flaring process.

In the as-forged condition, large differences in mechanical properties were found as a function of position and orientation. A large increase of strength properties is accompanied by a loss of ductility. Extremely low values of uniform elongation were found especially in the transverse samples located close to the flange edge. This latter result could indicate that the material located in the extreme position of the flange is close to reach the necking instability.

In the as-heat treated condition, no differences in terms of microstructure and mechanical properties were found among regions subjected to significant straining (flange) in comparison with those with little or no deformation (straight sections). A homogeneous distribution of microstructural and mechanical properties, regardless of both orientation and position of the specimens, was obtained across the whole component. These results reflect the normalizing effect of conventional hardening treatment for Jethete M152, obtaining a homogeneous lath martensite structure, and removing the cold-work introduced during the (cold) rotary forging operations.

Further work is still required to fully develop this innovative incremental cold forming method for the manufacturing of rotating parts. In the present work, limiting factors, such as buckling phenomenon and pickup defects on the top surface were found restricting the flange formation. In order to overcome these challenges, these limiting factors have to be tackled by means of combination of a modified rotary forging strategy, die design, application of simulation tools and a better lubrication selection.

\section{ACKNOWLEDGMENTS}

The work presented in this paper was funded by Innovate UK under SAMULET 2 Project 10.5 / Contract Ref TSB 113006. The author would like to acknowledge Rolls-Royce for their collaboration in the project and help provided, and also Dr. Olga Bylya for her useful comments and fruitful discussion.

\section{REFERENCES}

1. Comparision between cold rotary forging and conventional forging. Hua, Xinghui Han and Lin. s.l. : Journal of Mechanical Science and Technology, 2009, Vol. 23, pp. 2668-2678.

2. Recent development in orbital forging technology. J. Nowak, L. Madei, S. Ziolkiewicz, A. Plewinski, F. Grosman, M. Pietrzyk. 2008, Int. J. Metal Form, Vol. Suppl 1, pp. 387-390.

3. The significance of nutation angle in rotary forging. Standring, P.M. Advance technology of plasticity. 6th ICP 19-24 Sept 1999. Vol. III.

4. Characteristics of rotary forging as an advanced manufacturing tool. Standring, P.M. Part B, July 2001, Proceeding of the Institution of Mechanical Engineers, Vol. 215.

5. Orbital foring: a plausible alternative for bulk metal forming. Miroslav E. Plancak, Dragisa Z. Vilotic, Milentije C. Stefanovic, Dejan Z. Movrin , Igor Z. Kacmarcik,. 1, 2012, Journal of Trends in the development of Machinery and Associated Technology, Vol. 16, pp. 35-38.

6. Plastic deformation produced during indentation phase of rotary forging. P.M. Standring, J.R. Moon and E. Appleton. 1980, Metals Technology, pp. 159-166.

7. Effect of size of the cylindrical workpiece on the cold rotaryforging process. Hua, Xinghui Han and Lin. 2009, Materials and Design, Vol. 30, pp. 2802-2812.

8. Numerical analysis on rotary forging mechanism of a flange. Liu Gang, Yuan Shijian and Zhang Mingxue. 1, 2001, Journal of Material Science and Technology, Vol. 17, pp. 129-130.

9. Plastic deformation behaviours of cold rotary forging under different contact patterns by $3 D$ Elastic-Plastic FE Method. Hua, Xinghui Han and Lin. 8, 2009, Materials Transactions, Vol. 50, pp. 1949-1958.

10. Effect of the high-temperature deformation on the Ms temperature in a low $C$ martensitic stainless steel. M.A. AlvaradoMeza, E. Garc1'a-Sanchez, O. Covarrubias-Alvarado, A. SalinasRodriguez, M.P. Guerrero-Mata, and R. Cola's. 2, 2013, Journal of Materials Engineering and Performance, Vol. 22, pp. 345-350.

11. E8/E8M - 11: Standard Test Methods for Tension Testing of Metallic Materials.

12. Effect of orientation on hardness, strain accumulation, and fracture. K.S. Suresh, T. Kitashima, Y. Yamabe-Mitarai. 2014, Material Science \& Engineering A, Vol. 618, pp. 335-344.

13. Strengthening Mechanisms of Creep Resistant Tempered Martensitic Steel. Kouichi MARUYAMA, Kota SAWADA and Jun-ichi KOIKE: No. 6, pp. 641-653, s.l. : ISIJ International, 2001, Vol. Vol. 41.

14. Transformation of dislocation martensite in tempering secondary-hardening steel. I. V. Gorynin, V. V. Rybin, V. A. Malyshevskii, T. G. Semicheva, and L. G. Sherokhina. 9-10, 1999 : s.n., Metal Science and Heat Treatment, Vol. 41, pp. 377-383. 